\title{
Current Defies of Neurological Disorders
}

\author{
Anthony T Yeung ${ }^{1^{\star}}$ and Priyank Uniyal ${ }^{2^{*}}$ \\ ${ }^{1}$ University of New Mexico, School of Medicine, Albuquerque, New Mexico, USA \\ ${ }^{2}$ Wooridul Spine Hospital, Pohang, Korea
}

*Corresponding author: Anthony T Yeung, University of New Mexico, School of Medicine, Albuquerque, New Mexico, USA, Tel: (602) 944-2900; E-mail: ayeung@sciatica.com

Priyank Uniyal, Wooridul Spine Hospital, Pohang, Korea, Tel: +82 54240 6129; Fax: +82-54-240-6195; E-mail: priyank_uniyal@yahoo.com

Rec date: Oct 20, 2016; Acc date: Oct 24, 2016; Pub date: Oct 27, 2016

Copyright: () 2016 Yeung AT, et al. This is an open-access article distributed under the terms of the Creative Commons Attribution License, which permits unrestricted use, distribution, and reproduction in any medium, provided the original author and source are credited.

Citation: Yeung AT, Uniyal P (2016) Current Defies of Neurological Disorders. J Neurol Disord 4: e120. doi: 10.4172/2329-6895.1000e120

\section{Editor's Note}

Journal of Neurological Disorders Volume No 4, Issue 4 released its current issues with the theme "Challenges in therapeutic intervention for the suppression of neurological disorders". The current issue comprises innovative research articles covering all aspects of neurology and its related disorders.

Dai et al. study tried to explore the effect of endothelial progenitor cells (EPCs)-collagen sponge complex on the neovascularization of chronic cerebral ischemia following multiple burr holes $(\mathrm{MBH})$ surgery. The findings illustrate that in case of $\mathrm{MBH}$ surgery under chronic cerebral hypo-perfusion condition the EPCs-collagen sponge complex enhances angiogenesis and increases the blood flow perfusion in ischemic cerebral tissue [1].

Derakhshan's research article presented a case study on the successful opioid mono-therapy in migralepsy. This research explored a novel concept to address series of challenges faced by the patients suffering from migraine-triggered epilepsy [2].

Leng et al. tried to classify the musculocutaneous nerve variations depending on the origin. The findings states that the methods developed and followed are meaningful and easy to apply in surgical and clinical settings to manage the complex issues related to the nervous system. The study further suggested paying attention to the variation in MC during clinical investigation for the effective management of upper limb disorders [3].

Persinger, in the short communication discussed the consistently reflected cerebral dysfunction or damages due to subsequent to mild closed head injuries and protracted difficulties with adaptation [4]. Commentary article of Dias JC, had reported two cases on inflammatory polyneuropathy (PN) after bariatric surgery without nutritional deficiency [5]. Persinger and St-Pierre, in their case blog offered a simple solution for ulnar nerve paraesthesia following body impacts from mechanical energies [6]. Case report of Elleuch, had described an unusual case of a cranial $A B C$ occurring after long evolution of fronto-parietal FD in 16 years old girl [7].
Yeung AT, reviewed his 25 years' experience in transforaminal endoscopic surgery $[8,9]$ in a discussion of advancements made in the treatment of spinal pain with two summary articles of his clinical experience, "Transforaminal endoscopic surgery: It role in the treatment of painful conditions of an aging spine" and "Intradiscal therapy and transforaminal endoscopic decompression: opportunities and challenges for the future". The articles review the state of the art in minimally invasive spine surgery by focusing on the pain generators in the lumbar spine starting with the lumbar disc and expanding to decompression and ablation of nerves in the foramen.

\section{References}

1. Dai D, Zhang X, Lu Q, Wu Q, Huang Q, et al. (2016) EPCs-collagen sponge complex promotes neovascularization of chronic cerebral Ischemia following multiple burr hole (MBH) surgery. J Neurol Disord 4: 274

2. Derakhshan I (2016) Successful opioid monotherapy in migralepsy: A case series. J Neurol Disord 4: 275.

3. Leng L, Liu H, Wang T, Liu L, Si D (2016) Classifying musculocutaneous nerve variations depending on the origin. J Neurol Disord 4: 276.

4. Persinger MA (2016) Answers to two questions consistently reflect cerebral dysfunction or damage subsequent to mild closed head injuries and protracted difficulties with adaptation. J Neurol Disord 4: 277.

5. Dias JC, Vidal CM, Freitas MRG (2016) Inflammatory polyneuropathy after bariatric surgery: Report of two cases. J Neurol Disord 4:278.

6. Persinger MA, Pierre LS (2016) A simple accommodation for ulnar nerve paraesthesia following body impacts from mechanical energies. J Neurol Disord 4: 280.

7. Elleuch W, Briki S, Karray F, Dhouib M, Abdelmoula M (2016) Aneurysmal bone cyst in cranial fibrous dysplasia: A case report. J Neurol Disord 4: 281.

8. Yeung, AT, Gore SR (2011) In-vivo endoscopic visualization of pathoanatomy in symptomatic degenerative conditions of the lumbar spine II: Intradiscal, foraminal, and central canal decompression. Surg Technol Int. 299-319.

9. Yeung AT, Gore SA (2001) Evolving methodology in treating discogenic back pain by selective endoscopic discectomy $\left(\mathrm{SED}^{\mathrm{rt}}\right)$ and thermal annuloplasty. J Minim Invasive Spine Surg Tech 1: 8-16. 